\title{
DEVELOPMENT AND VALIDATION OF A STABILITY INDICATING RP-HPLC METHOD FOR THE DETERMINATION OF POTENTIAL DEGRADATION PRODUCTS OF DIFLUPREDNATE IN OPHTHALMIC EMULSION
}

\author{
MURLIDHAR V. ZOPE ${ }^{1,2}$, RAHUL M. PATEL ${ }^{2}$, ASHWINI KUMAR PATEL ${ }^{2}$, SAMIR G. PATEL ${ }^{1 *}$ \\ ${ }^{1}$ Ramanbhai Patel College of Pharmacy, Charotar University of Science and Technology, Charusat Campus, Changa, 388421, Ta. Petlad, \\ Dist.: Anand, Gujarat, India, ${ }^{2}$ Sun Pharma Advanced Research Company Ltd., Tandalja, Vadodara, Gujarat, India \\ Email: samirpatel.ph@charusat.ac.in
}

Received: 29 Mar 2018 Revised and Accepted: 10 Aug 2018

\section{ABSTRACT}

Objective: The objective of the current study was to develop and validate a simple, robust, precise and accurate RP-HPLC (reverse phase-high performance liquid chromatography) method for the quantitative determination of potential degradation products of Difluprednate (DIFL) in the ophthalmic emulsion.

Methods: Chromatographic separation was achieved on the YMC pack ODS-AQ $(150 \times 4.6) \mathrm{mm}, 3 \mu \mathrm{m}$ column with a mobile phase containing a gradient mixture of mobile phase A (0.02M Ammonium formate buffer $\mathrm{pH} 4.5$ adjusted with formic acid) and Acetonitrile as mobile phase $\mathrm{B}$, at flow rate of $1.5 \mathrm{ml} / \mathrm{min}$ and with $\mathrm{UV}$ detection at $240 \mathrm{~nm}$.

Results: The peak retention time of DIFL was found at about $17.2 \mathrm{~min}$, the RRT of degradation product-1 (DP-1), degradation product-2 (DP-2), and degradation product-3 (DP-3), were found to be about $0.49,0.65$ and 0.79 respectively (calculated with respect to Difluprednate). Stress testing was performed in accordance with an ICH (international council for harmonisation) guideline Q1A (R2) [1]. The method was validated as per ICH guideline Q2 (R1)[2]. The calibration curve was found to be linear in the concentration range of 0.1 to $0.75 \mu \mathrm{g} / \mathrm{ml}$ for Difluprednate, DP-1, DP-2 and DP-3. The LOD (Limit of detection) was found to be $0.1 \mu \mathrm{g} / \mathrm{ml}$ and LOQ (Limit of quantification) of $0.15 \mu \mathrm{g} / \mathrm{ml}$ for Difluprednate, DP-1, DP-2 and DP-3 respectively. The recovery from LOQ to $150 \%$ was within $90-110 \%$. The forced degradation data confirms the stability indicating the nature of the method.

Conclusion: A simple, robust, precise and accurate RP-HPLC method for the quantitative determination of potential degradation products of Difluprednate in the ophthalmic emulsion was developed and validated.

Keywords: Difluprednate, Stability indicating, RP-HPLC, Degradation products, Forced degradation

(C) 2018 The Authors. Published by Innovare Academic Sciences Pvt Ltd. This is an open-access article under the CC BY license (http://creativecommons.org/licenses/by/4.0/ DOI: http://dx.doi.org/10.22159/ijpps.2018v10i9.26342

\section{INTRODUCTION}

Difluprednate (DIFL) [(6S,8S,9R,10S,11S,13S,14S,17R)-17-(2-Acetyloxyacetyl)-6,9-difluoro-11-hydroxy-10,13-imethyl-3-oxo-6,7,8,11,12, 14,15,16-octahydrocyclopenta[a] phenanthren-17-yl] butanoate (fig. 1) is a glucocorticoid receptor agonist and a diflurinated derivative of prednisolone having anti-inflammatory activity. DIFL ophthalmic emulsion is a topical formulation of DIFL that is an ophthalmic corticosteroid emulsion for topical instillation [4-10].

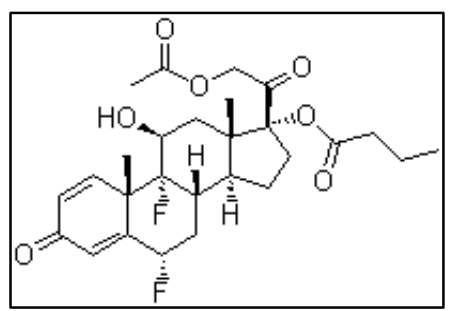

Fig. 1: Chemical structure of DIFL

Literature survey revealed that RP-HPLC method has been reported for the estimation of DIFL from biological matrices, for assay in bulk drug as well as in eye drops [5]. The UV-Visible spectrometric method was also reported for estimation of DIFL [10]. DIFL and its formulations are not official in any pharmacopeia.

To the best of our knowledge, no stability indicating reverse-phase highperformance liquid chromatography [RP-HPLC] method has been reported for the determination of DIFL and its related impurities in the emulsion based eye drops. Very less work has been done on the quantification of related substances of DIFL in the ophthalmic emulsion hence a simple robust and sensitive stability indicating RP-HPLC method was developed and validated for determination of DIFL and its related impurities in the ophthalmic emulsion as per the ICH guidelines [1-3].

Three potential degradation products were observed in the marketed products and in the degradation studies, the identified degradation products were enriched, isolated and purified. These purified degradation products were degradation product-1(DP-1), degradation product-2 (DP-2) and degradation product-3 (DP-3) which were then used to validate the method. The specification limit for the three degradation products and unknown impurities is considered as $1.0 \%$ based on the maximum daily dose as per ICH guideline [11]. The main aim of this research work was to develop a stability indicating the RP-HPLC method for determination of degradation products of DIFL in the ophthalmic emulsion.

Stability indicating RP-HPLC method is defined as a validated method having the ability to specifically quantitate the analyte in the presence of excipients, degradation products, and process impurities. Due to the impact of stress (hydrolysis, oxidation, temperature and photolytic) during shelf life and instability studies, various degradation products shall be formed, specific quantification of these degradation products provides additional assurance of the stability indicating nature of the method [12-14].

\section{MATERIALS AND METHODS}

\section{Chemicals and reagents}

DIFL (active pharmaceutical ingredient) and DIFL ophthalmic emulsion were procured as a gratis sample from Sun Pharma, Baroda. Market samples of Flupred(c) were also received from Sun 
pharma; other market samples were procured from a local pharmacy. Ammonium formate, formic acid and sodium hydroxide (AR-grade) were purchased from Merck. HPLC grade acetonitrile was purchased from Merck, AR-grade hydrochloric acid and 30\% hydrogen peroxide was purchased from Rankem. DP-1, DP-2, and DP-3 were enriched, isolated and purified in-house.

\section{Instruments}

Chromatography was performed on Waters HPLC 2695 equipped with quaternary pumps with PDA (Photodiode array) detector. The chromatographic separation was performed using YMC Pack ODS$\mathrm{AQ} ® \mathrm{C} 18$ reverse phase column $(150 \times 3) \mathrm{mm}, 3 \mu \mathrm{m}, 110 \AA \tilde{A}, \mathrm{YMC}$ Japan. Data acquisition and integrations were performed using empower 3 software.

\section{Methods}

\section{Chromatographic conditions}

Chromatographic separation was performed in gradient mode with a flow rate of $1.5 \mathrm{ml} / \mathrm{min}$ consisting of mobile phase-A $(0.02 \mathrm{M}$ ammonium formate, $\mathrm{pH} 4.5$ ) and an organic phase (Acetonitrile) as mobile phase-B with the column temperature set to $40{ }^{\circ} \mathrm{C}$. The injection volume was $20 \mu \mathrm{l}$, and UV detection of DIFL and its degradation products was accomplished at $240 \mathrm{~nm}$. The column was YMC pack ODS-AQ $(150 \times 4.6) \mathrm{mm}, 3 \mu \mathrm{m}$. The gradients used was $0 \mathrm{~min}$ (A-75\% and B-25\%), 10 min (A-55\% and B-45\%), 15 min (A-55\% and B-45\%), 20 min (A-20\% and B-80\%), 28 min (A-20\% and B-80\%), 30 $\min (A-75 \%$ and $B-25 \%)$ and 36 min (A-75\% and B-25\%).

\section{Preparation of solutions}

\section{Preparation of buffer solution}

Dissolved $1.29 \mathrm{gm}$ of Ammonium formate in $1000 \mathrm{ml}$ of milli-Q water, sonicated for $5 \mathrm{~min}$ to dissolve. Adjusted the $\mathrm{pH}$ of the solution to 4.5 with diluted Formic Acid $(20 \% \mathrm{v} / \mathrm{v})$ and filtered through $0.45 \mu \mathrm{mNylon}$ membrane filter paper.

\section{Preparation of standard solutions}

$5 \mathrm{mg}$ of DIFL was dissolved in $20 \mathrm{ml}$ of acetonitrile to prepare a standard stock solution of $250 \mathrm{ppm} ; 2 \mathrm{ml}$ of the standard stock solution was further diluted to $100 \mathrm{ml}$ with acetonitrile $(5 \mathrm{ppm}$ system suitability solution).

\section{Preparation of sample solutions}

$1 \mathrm{ml}$ of DIFL ophthalmic emulsion $0.05 \% \mathrm{w} / \mathrm{v}$ was diluted up to 10 $\mathrm{ml}$ with acetonitrile; sonicated the solution for $5 \mathrm{~min}$ and centrifuged at $5000 \mathrm{rpm}$ for $10 \mathrm{~min}$ and the clear supernatant solution was injected in the chromatograph.

\section{Preparation of placebo solutions}

$1 \mathrm{ml}$ of placebo was diluted to $10 \mathrm{ml}$ with acetonitrile; sonicated for $5 \mathrm{~min}$ and centrifuged at $5000 \mathrm{rpm}$ for $10 \mathrm{~min}$ and the clear supernatant solution was injected into the chromatographic system, and the chromatogram was recorded.

\section{Preparation of DP-1 stock solutions}

$2.5 \mathrm{mg}$ of purified DP-1 was dissolved in $10 \mathrm{ml}$ of acetonitrile and further diluted to $50 \mathrm{ml}$ with acetonitrile.

\section{Preparation of DP-2 stock solutions}

$2.5 \mathrm{mg}$ of purified DP-2 was dissolved in $10 \mathrm{ml}$ of acetonitrile and further diluted to $50 \mathrm{ml}$ with acetonitrile.

\section{Preparation of DP-3 stock solutions}

$2.5 \mathrm{mg}$ of purified DP-3 was dissolved in $10 \mathrm{ml}$ of acetonitrile and further diluted to $50 \mathrm{ml}$ with acetonitrile.

\section{Validation}

The optimized analytical method was validated for system suitability, linearity and range, precision, limit of detection, limit of quantitation, accuracy from LOQ to $150 \%$ of the specification limit
(1\% for all impurities) and robustness in accordance with $\mathrm{ICH}$ guidelines for analytical procedures Q2 (R1).

\section{System suitability}

System suitability parameters were studied to verify the system performance and suitability of the method before every experiment. Six replicate injection of DIFL standard solution $[5 \mu \mathrm{g} / \mathrm{ml}]$ were analyzed using the developed method. Factors such as theoretical plate count, tailing factor, percent relative standard deviation [\% RSD] of peak area and retention time were taken into consideration for testing system suitability.

\section{Linearity and range}

The linearity was evaluated at eight concentration levels in the range between 0.05 to $0.75 \mu \mathrm{g} / \mathrm{ml}$ for DIFL and three degradation products. A calibration curve was plotted by plotting concentration against corresponding peak area, and linearity was determined using least square regression analysis. The analytical range was established by the highest and lowest concentrations of analyte where acceptable linearity obtained.

\section{Accuracy and method precision}

The method precision and accuracy were carried out by preparing and analyzing the sample as per the method and spiking the sample with three impurities at 4 different level (LOQ, 50\%, 100\% and $150 \%$ of specification level) in three replicates preparation at each level. The concentration for each impurity at LOQ $50 \%, 100 \%$ and $150 \%$ was $0.15 \mu \mathrm{g} / \mathrm{ml}, \quad 0.25 \mu \mathrm{g} / \mathrm{ml}, \quad 0.5 \mu \mathrm{g} / \mathrm{ml}$ and $0.75 \mu \mathrm{g} / \mathrm{ml}$ respectively. The percentage recovery and percentage relative standard deviation were taken into consideration for testing accuracy and precision at each level.

\section{Intermediate precision (Ruggedness)}

The ruggedness of the method was carried out by spiking the sample preparation with the three impurities at $100 \%$ level in six replicates. The samples were analyzed by the different analyst using the different column on a different system. The \% RSD of the 9 determination; three from method precision at $100 \%$ level and six from ruggedness has been reported.

\section{LOD and LOQ}

LOD and LOQ of the developed method were calculated from the standard deviation of the y-intercepts and slope of the calibration curve of DIFL and three impurities using the following formula:

$$
\begin{aligned}
& L O D=\frac{3.3 \alpha}{S} \ldots \ldots \ldots \ldots \ldots \ldots \ldots \ldots \ldots \ldots \ldots \ldots \ldots \ldots \ldots \ldots \ldots \ldots \\
& L O Q
\end{aligned}
$$

Where $\alpha$ is the standard deviation of the y-intercepts and $S$ is the slope of the calibration curve.

\section{Relative response factor (RRF)}

Relative response factor of the three impurities was calculated using slope of the regression line for each impurity using the following formula:

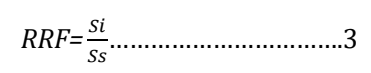

Where $S i$ is slope of impurity standard and $S s$ is slope of drug standard.

\section{Forced degradation study}

\section{Acidic degradation}

Accurately pipetted and transferred $1 \mathrm{ml}$ sample solution into a 10 $\mathrm{ml}$ volumetric flask, added $1 \mathrm{ml}$ acetonitrile mixed and added $0.5 \mathrm{ml}$ of $0.2 \mathrm{M}$ Hydrochloric acid solution and refluxed at $60{ }^{\circ} \mathrm{C}$ for $10 \mathrm{hr}$, cooled the resulting solution at room temperature and neutralized the sample using $0.5 \mathrm{ml}$ of $0.2 \mathrm{M}$ sodium hydroxide solution and diluted up to $10 \mathrm{ml}$ with acetonitrile $(50 \mu \mathrm{g} / \mathrm{ml}$ of DIFL). Centrifuged at $5000 \mathrm{rpm}$ for 10 minute and the supernatant solution was 
injected into the chromatographic system and the chromatogram was recorded.

\section{Alkaline degradation}

Accurately pipetted and transferred $1 \mathrm{ml}$ sample solution into a 10 $\mathrm{ml}$ volumetric flask, added $1 \mathrm{ml}$ acetonitrile mixed and added $0.5 \mathrm{ml}$ of $0.025 \mathrm{M}$ sodium hydroxide solution and refluxed it at $40{ }^{\circ} \mathrm{C}$ for $6 \mathrm{hr}$, cooled the resulting solution at room temperature and neutralized the sample using $0.5 \mathrm{ml}$ of $0.025 \mathrm{M}$ hydrochloric acid solution and diluted up to $10 \mathrm{ml}$ with acetonitrile $(50 \mu \mathrm{g} / \mathrm{ml}$ of DIFL). Centrifuged at $5000 \mathrm{rpm}$ for $10 \mathrm{~min}$ and the supernatant solution was injected into the chromatographic system, and the chromatogram was recorded.

\section{Thermal degradation}

Accurately pipetted and transferred $1 \mathrm{ml}$ sample solution into a 10 $\mathrm{ml}$ volumetric flask, added $1 \mathrm{ml}$ acetonitrile; mixed and kept in a preheated oven at $80^{\circ} \mathrm{C}$ for $72 \mathrm{hr}$, cooled the resulting solution at room temperature and diluted it up to $10 \mathrm{ml}$ with acetonitrile $(50$ $\mu \mathrm{g} / \mathrm{ml}$ of DIFL). Centrifuged at $5000 \mathrm{rpm}$ for 10 minute and the supernatant solution was injected into the chromatographic system, and the chromatogram was recorded.

\section{Oxidative degradation}

Accurately pipetted and transferred $1 \mathrm{ml}$ sample solution into a 10 $\mathrm{ml}$ volumetric flask, added $1 \mathrm{ml}$ acetonitrile mixed and added $1 \mathrm{ml}$ of $6 \%$ hydrogen peroxide solution and refluxed it at $60{ }^{\circ} \mathrm{C}$ for $3 \mathrm{hr}$, cooled the resulting solution at room temperature and diluted up to
$10 \mathrm{ml}$ with acetonitrile $(50 \mu \mathrm{g} / \mathrm{ml}$ of DIFL). Centrifuged at $5000 \mathrm{rpm}$ for 10 minute and the supernatant solution was injected into the chromatographic system and the chromatogram was recorded.

\section{Photolytic degradation}

$5 \mathrm{ml}$ of the sample was exposed to UV light at 254 and $360 \mathrm{~nm}$ for 7 d. accurately pipetted and transferred $1 \mathrm{ml}$ of the exposed sample into a $10 \mathrm{ml}$ volumetric flask, diluted up to $10 \mathrm{ml}$ with acetonitrile $(50 \mu \mathrm{g} / \mathrm{ml}$ of DIFL). Centrifuged at $5000 \mathrm{rpm}$ for $10 \mathrm{~min}$ and the supernatant was injected into the chromatographic system and the chromatograms were recorded.

\section{RESULTS}

\section{Method development and optimization}

The purpose of this method was to separate the potential known and unknown degradation products of DIFL in shorter run time. C18 column from various manufacturers was tried, and good peak separation was observed in YMC pack ODS-AQ which is polar imbedded reverse phase column. Various buffer including phosphate and formate were tried in the $\mathrm{pH}$ range of 3.0 to 7.0. The gradient has been optimized after selection of suitable buffer, $\mathrm{pH}$ and column. Based on the optimization trial final method was developed and validated as per ICH guideline [2].

The optimized chromatographic condition was shown in table 1 and the typical HPLC chromatogram of standard and sample spiked with degradation product were shown in (fig. 2 and 3 ) and its combined PDA spectrum was shown in fig. 5.

Table 1: Optimised chromatographic condition for the estimation of DIFL and potential degradation products

\begin{tabular}{ll}
\hline Parameter & Condition \\
\hline Mobile phase & $0.02 \mathrm{M}$ ammonium formate buffer $\mathrm{pH}$ 4.5: acetonitrile [80:20 v/v]. \\
Gradient Program & The gradients used are 0 min (A-75\% and B-25\%), 10 min (A-55\% and B-45\%), 15 min (A-55\% and B-45\%), 20 min (A- \\
& $20 \%$ and B-80\%), 28 min (A-20\% and B-80\%), 30 min (A-75\% and B-25\%) and 37 min (A-75\% and B-25\%). \\
Diluent & Acetonitrile \\
Column & YMC pack ODS AQ (150 mm $\times 4.6 \mathrm{~mm}) 3 \mu \mathrm{m}$ \\
Column temperature & $40{ }^{\circ} \mathrm{C}$ \\
Detection wavelength & $240 \mathrm{~nm}$ \\
Injection volume & $20 \mu \mathrm{l}$ \\
Flow rate & $1.5 \mathrm{ml} / \mathrm{min}$ \\
Runtime & $36 \mathrm{~min}$ \\
\hline
\end{tabular}

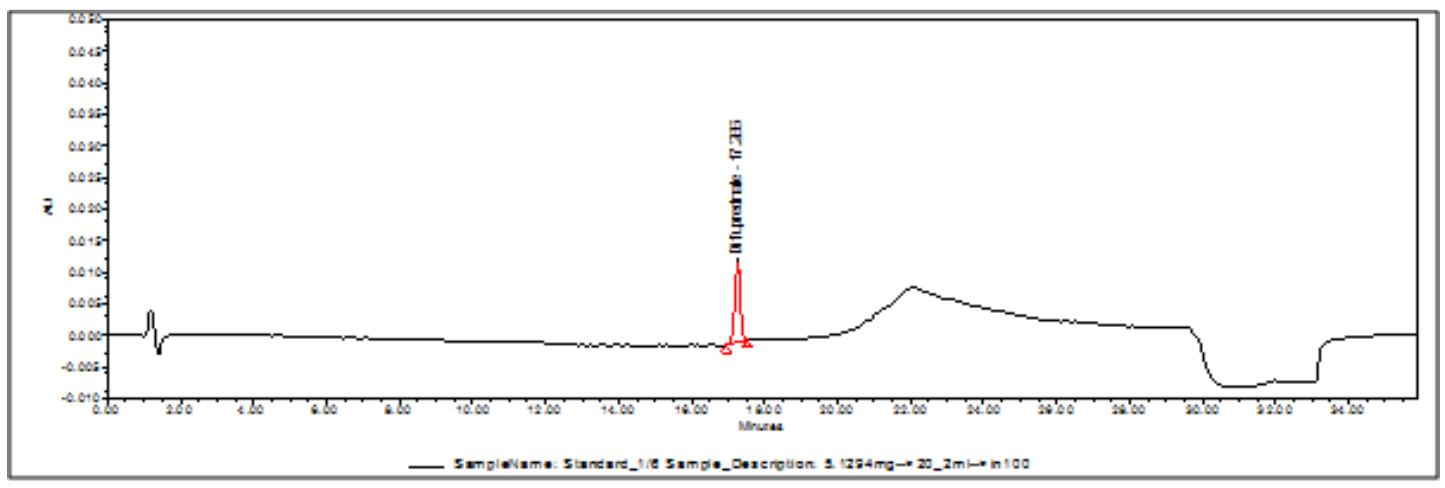

Fig. 2: HPLC chromatogram of standard

\section{Method validation}

The developed method was validated as per ICH guideline [1-3].

\section{System suitability}

The developed method has produced a theoretical plate above 5000 for DIFL and three impurities with tailing factor less than 2 . Similarly, the \%RSD of peak area and retention time for DIFL peak was less than 5 , which ensure the suitability of the developed method. The results of the system suitability study were summarised in table 2 .

\section{Acceptance criteria}

The relative standard deviation of six replicate injections for peak area should not be more than $5.0 \%$. The tailing factor should not be more than 2. The theoretical plates should not be less than 5000 .

\section{Linearity and range}

Eight point calibration curve was obtained in concentration ranges from $0.10-0.75 \mu \mathrm{g} / \mathrm{ml}$ for DIFL and its three impurities. The response of the drug was found to be linear in the selected concentration range and the correlation coefficient for DIFL, DP-1, DP-2 and DP-3 were 


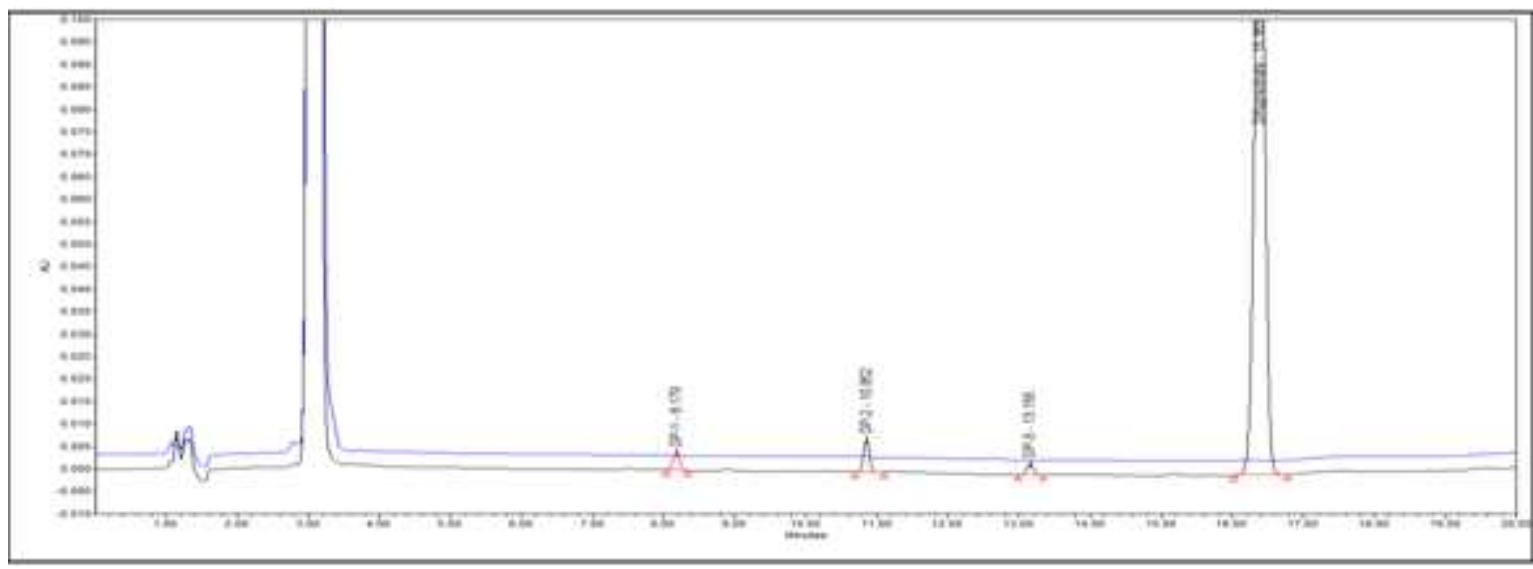

Fig. 3: HPLC chromatogram of sample spiked with impurities (DP-1, DP-2 and DP-3)

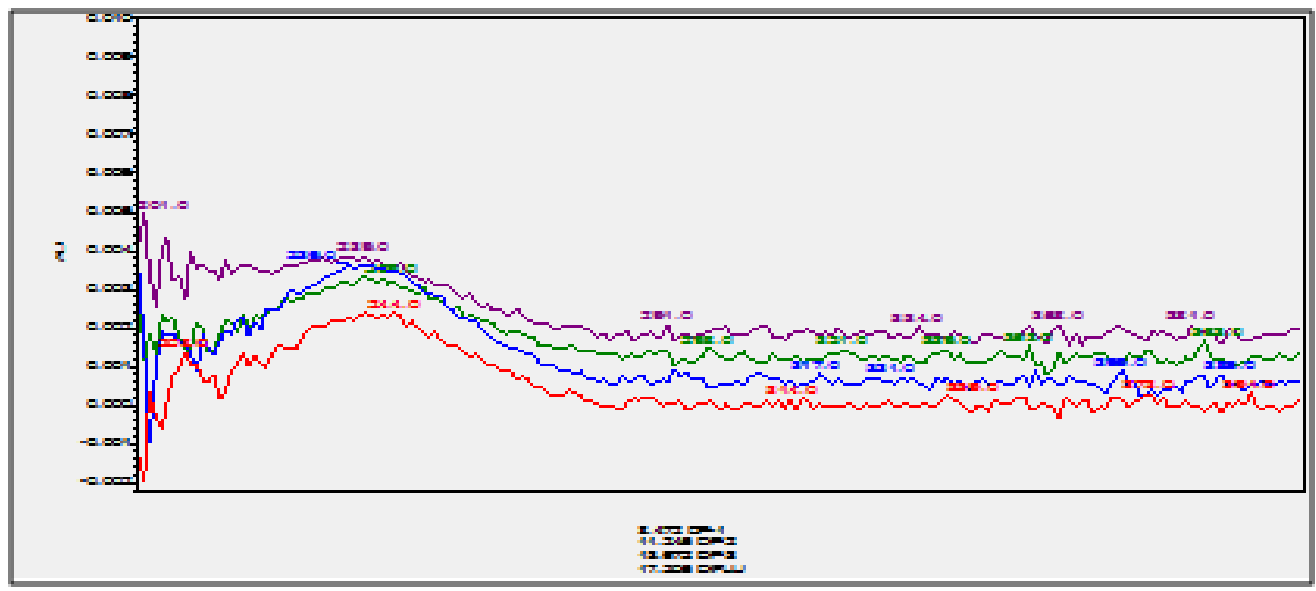

Fig. 4: PDA spectrum of DIFL, DP-1, DP-2 and DP-3

\section{Precision}

The developed method had shown \% RSD less than 5 for both method precision (precision and recovery study) and intermediate precision study, which ensures precision of the developed method. The results of the precision study were summarised in table 4 and 7.

\section{Limit of detection and limit of quantification}

LOD and LOQ were estimated from the standard deviation of the Y-intercepts and slope of the calibration curve of DIFL and its impurities. This showed that the developed method can detect and quantify very low concentrations of DIFL in the presence of its degrading products; therefore obtained data proves the sensitivity of the developed method for quantification of impurities.

\section{Accuracy and method precision}

The percentage recovery of the sample spiked with the known impurities was within $100 \pm 10 \%$, which ensures the accuracy of the developed method. The results of recovery studies were summarised in table 5-8.

\section{Robustness}

As per ICH guideline, the prepared solution was analyzed as per the method with a small but deliberate change in chromatographic conditions as listed below table 9. Change in flow rate, temperature and $\mathrm{pH}$ were studied.

Table 2: System suitability of the developed RP-HPLC method

\begin{tabular}{|c|c|c|c|c|c|}
\hline \multirow[t]{2}{*}{ Parameters } & \multirow{2}{*}{$\begin{array}{l}\text { Name of drug } \\
\text { DIFL }\end{array}$} & \multicolumn{4}{|l|}{ Acceptance criteria } \\
\hline & & DP-1 & DP-2 & DP-3 & \\
\hline Retention time & 17.24 & 8.48 & 11.27 & 13.70 & --- \\
\hline Theoretical plates [N] & 109364 & 16524 & 43369 & 44606 & $>5000$ \\
\hline Tailing factor & 0.93 & 0.84 & 0.96 & 0.94 & $<2$ \\
\hline Resolution & NA & 11.59 & 10.13 & 12.91 & $>2$ \\
\hline$\%$ RSD of Peak area* & 0.41 & NA & NA & NA & $<5$ \\
\hline$\%$ RSD of Retention time* & 0.26 & NA & NA & NA & $<2$ \\
\hline
\end{tabular}

${ }^{*} \mathrm{~N}$ (Number of measurements) =6, NA: Not applicable 
Table 3: Linearity, range and RRF of the developed RP-HPLC method

\begin{tabular}{|c|c|c|c|c|c|}
\hline \multirow[t]{2}{*}{$\%$ of specification level } & \multirow[t]{2}{*}{ Conc. in $\mu \mathrm{g} / \mathrm{ml}$} & \multicolumn{4}{|c|}{ Calculated area* } \\
\hline & & DIFL & DP-1 & DP-2 & DP-3 \\
\hline 10 & 0.05 & ND & NA & NA & NA \\
\hline 20 & 0.1 & 4.4 & 2 & 3.61 & 1.86 \\
\hline 30 & 0.15 & 4.5 & 3.8 & 4.43 & 3.99 \\
\hline 50 & 0.25 & 7.86 & 6.31 & 7.45 & 6.24 \\
\hline 80 & 0.4 & 12.81 & 12.04 & 13.03 & 10.97 \\
\hline 100 & 0.5 & 15.66 & 14.52 & 16.62 & 13.72 \\
\hline 120 & 0.6 & 17.33 & 18.74 & 20.32 & 17.24 \\
\hline 150 & 0.75 & 23.35 & 23.99 & 25.77 & 21.63 \\
\hline Correlation Coefficient (r) & & 0.99686 & 0.99837 & 0.99818 & 0.99802 \\
\hline Y intercept & & 1.10345 & -1.14013 & -0.1899 & -0.60816 \\
\hline \%Y-Intercept & & 27.4132 & 31.6629 & 28.5376 & 27.3023 \\
\hline Slope & & 0.56207 & 0.46273 & 0.5065 & 0.4774 \\
\hline RRF & & 1 & 1.13 & 1.18 & 1.10 \\
\hline
\end{tabular}

${ }^{*}$ Calculated Area= Area count/1000, Conc: concentration, RRF: relative response factor, NA: Not applicable, ND: Not detected.

Table 4: Intermediate precision (Ruggedness) of the developed RP-HPLC method

\begin{tabular}{llll}
\hline Sample ID & Component & \\
\cline { 2 - 4 } & DP-1 & DP-2 & DP-3 \\
\hline MP Set-1 & 98.8 & 104.0 & 94.1 \\
MP Set-2 & 96.4 & 106.1 & 93.8 \\
MP Set-3 & 98.8 & 100.2 & 97.3 \\
IP Set-1 & 101.3 & 98.2 & 96.6 \\
IP Set-2 & 98.7 & 97.4 & 97.0 \\
IP Set-3 & 102.9 & 98.1 & 97.2 \\
IP Set-4 & 100.3 & 97.5 & 96.9 \\
IP Set-5 & 102.0 & 97.0 & 97.1 \\
IP Set-6 & 102.3 & 97.7 & 96.4 \\
*Mean recovery & $100.17 \pm 2.14$ & $99.58 \pm 3.29$ & $96.27 \pm 1.40$ \\
\% RSD & 2.14 & 3.30 & 1.45 \\
\hline
\end{tabular}

$\mathrm{MP}=$ Method precision, $\mathrm{IP}=$ Intermediate precision, ${ }^{*}$ mean \pm SD (Standard deviation), $\mathrm{N}=9$.

Table 5: Accuracy at LOQ of the developed RP-HPLC method

\begin{tabular}{lllll}
\hline Component & \multicolumn{2}{l}{ Recovery at LOQ level } & \multicolumn{2}{c}{ \% Avg. recovery* $^{*}$} \\
\cline { 2 - 4 } & \% Recovery & & Set-3 & \\
\cline { 2 - 4 } & Set-1 & Set-2 & 90.4 & $93.6 \pm 2.81$ \\
DP-1 & 95.0 & 95.4 & 92.1 & $91.4 \pm 2.69$ \\
DP-2 & 88.5 & 93.7 & 96.7 & $95.7 \pm 0.97$ \\
DP-3 & 95.8 & 94.7 & 99.9 & $101.9 \pm 2.31$ \\
DIFL & 104.4 & 101.4 & 1.0 \\
\hline
\end{tabular}

$* \mathrm{~N}=3$, mean $\pm \mathrm{SD}$, Avg= Average

Table 6: Accuracy at $\mathbf{5 0 \%}$

\begin{tabular}{lllll}
\hline Component & \multicolumn{2}{l}{ Recovery at $\mathbf{5 0 \%}$ of specification level } & \\
\cline { 2 - 4 } & \% Recovery & & Set-3 & \% Avg. recovery* \\
\cline { 2 - 4 } & Set-1 & Set-2 & 98.6 & $102.0 \pm 3.00$ \\
\hline DP-1 & 103.1 & 104.3 & 105.3 & $103.6 \pm 2.08$ \\
DP-2 & 101.3 & 104.3 & 96.9 & $101.1 \pm 3.80$ \\
DP-3 & 102.1 & 104.3 & 98.1 & $98.7 \pm 1.04$ \\
DIFL & 98.1 & 99.9 & 2.0 \\
\hline
\end{tabular}

$* \mathrm{~N}=3$, mean $\pm \mathrm{SD}, \mathrm{Avg}=$ Average

Table 7: Accuracyat 100\%

\begin{tabular}{|c|c|c|c|c|c|}
\hline \multirow[t]{3}{*}{ Component } & \multicolumn{5}{|c|}{ Recovery at $100 \%$ of specification level } \\
\hline & \multicolumn{3}{|c|}{ \% Recovery } & \multirow[t]{2}{*}{$\%$ Avg. recovery* } & \multirow[t]{2}{*}{ \% RSD } \\
\hline & Set-1 & Set-2 & Set-3 & & \\
\hline DP-1 & 98.8 & 96.4 & 98.8 & $98.0 \pm 1.39$ & 1.4 \\
\hline DP-2 & 104.0 & 106.1 & 100.2 & $103.4 \pm 2.99$ & 2.9 \\
\hline DP-3 & 94.1 & 93.8 & 97.3 & $95.1 \pm 1.94$ & 2.0 \\
\hline DIFL & 101.5 & 101.7 & 101.7 & $101.6 \pm 0.12$ & 0.1 \\
\hline
\end{tabular}

${ }^{*} \mathrm{~N}=3$, mean $\pm \mathrm{SD}$, Avg=Average 
Table 8: Accuracy at $\mathbf{1 5 0 \%}$

\begin{tabular}{|c|c|c|c|c|c|}
\hline \multirow[t]{3}{*}{ Component } & \multicolumn{5}{|c|}{ Recovery at $150 \%$ of specification level } \\
\hline & \multicolumn{3}{|c|}{ \% Recovery } & \multirow[t]{2}{*}{$\%$ Avg. recovery* } & \multirow[t]{2}{*}{ \% RSD } \\
\hline & Set-1 & Set-2 & Set-3 & & \\
\hline DP-1 & 101.2 & 97.5 & 107.2 & $102.0 \pm 4.90$ & 4.8 \\
\hline DP-2 & 98.8 & 102.4 & 99.0 & $100.1 \pm 2.02$ & 2.0 \\
\hline DP-3 & 98.2 & 97.9 & 96.0 & $97.4 \pm 1.19$ & 1.2 \\
\hline DIFL & 101.1 & 101.1 & 101.3 & $101.2 \pm 0.12$ & 0.1 \\
\hline
\end{tabular}

${ }^{*} \mathrm{~N}=3$, mean $\pm \mathrm{SD}$, Avg $=$ Average.

Table 9: Robustness of the developed RP-HPLC method

\begin{tabular}{|c|c|c|c|c|c|c|}
\hline Parameter & Mean area* & \% RSD (area) & Retention* time & \%RSD for RT & USP plate count & USP tailing \\
\hline Column temperature $45^{\circ} \mathrm{C}(+)$ & $132.93 \pm 0.90$ & 0.68 & $16.9 \pm 0.03$ & 0.20 & 40207 & 0.87 \\
\hline Column temperature $35^{\circ} \mathrm{C}(-)$ & $139.21 \pm 0.77$ & 0.55 & $17.77 \pm 0.05$ & 0.26 & 105038 & 0.94 \\
\hline Flow rate $1.7 \mathrm{ml} / \mathrm{min}(+)$ & $121.39 \pm 1.22$ & 1.00 & $16.06 \pm 0.01$ & 0.06 & 38335 & 0.93 \\
\hline Flow rate $1.3 \mathrm{ml} / \mathrm{min}(-)$ & $156.66 \pm 0.81$ & 0.52 & $18.25 \pm 0.01$ & 0.06 & 119926 & 0.92 \\
\hline pH $4.7(+)$ & $150.09 \pm 2.07$ & 1.38 & $16.27 \pm 0.02$ & 0.14 & 65417 & 0.98 \\
\hline $\mathrm{pH} 4.3(-)$ & $151.8 \pm 5.47$ & 3.6 & $16.58 \pm 0.04$ & 0.25 & 65305 & 0.95 \\
\hline
\end{tabular}

$\mathrm{N}=6, \mathrm{RT}=$ Retention time, ${ }^{*}$ mean $\pm \mathrm{SD}$

\section{Application of the validated method for analysis of a market sample}

The developed method was used to determine the \% impurities of the marketed samples. The results of the assay were summarised in table 10 and the summary of the validation parameter was summarised in table 11, it was confirmed that the market sample has the impurities. Amongst it, the major impurities were DP-1, DP-2 and DP-3.

Table 10: Related substances of DIFL in ophthalmic emulsion

\begin{tabular}{|c|c|c|c|c|c|}
\hline Sample details & DP1 (\%) & DP2 (\%) & DP3 (\%) & \% Unknown & \%Total impurities \\
\hline DIFL Ophthalmic emulsion $0.05 \% \mathrm{w} / \mathrm{v}$ & 0.42 & 0.59 & 0.15 & 0.30 & 1.46 \\
\hline
\end{tabular}

Table 11: Summary of validation parameters of developed RP-HPLC method

\begin{tabular}{llllll}
\hline S. No. & Validation parameter & DIFL & DP-1 & DP-2 & DP-3 \\
\hline 1 & Linearity range $(\mu \mathrm{g} / \mathrm{ml})$ & $0.10-0.75$ & $0.10-0.75$ & $0.10-0.75$ & $0.10-0.75$ \\
2 & Precision & & & \\
& Method precision(\%RSD)* & NA & 1.41 & 2.89 & 2.04 \\
& Intermediate precision(\%RSD)* & NA & 1.38 & 0.42 & 0.29 \\
3 & Accuracy $(\%$ recovery)* & $101.6 \pm 0.12$ & $98.0 \pm 1.39$ & $103.4 \pm 2.99$ & $95.1 \pm 1.94$ \\
4 & LOD $(\mu \mathrm{g} / \mathrm{ml})$ & 0.1 & 0.1 & 0.1 & 0.1 \\
5 & LOQ $(\mu \mathrm{g} / \mathrm{ml})$ & 0.15 & 0.15 & 0.15 & 0.15 \\
6 & Specificity & Specific & Specific & Specific & Specific \\
7 & Robustness & Robust & Robust & Robust & Robust \\
\hline
\end{tabular}

${ }^{*}$ mean \pm SD, Sr. No=Serial number

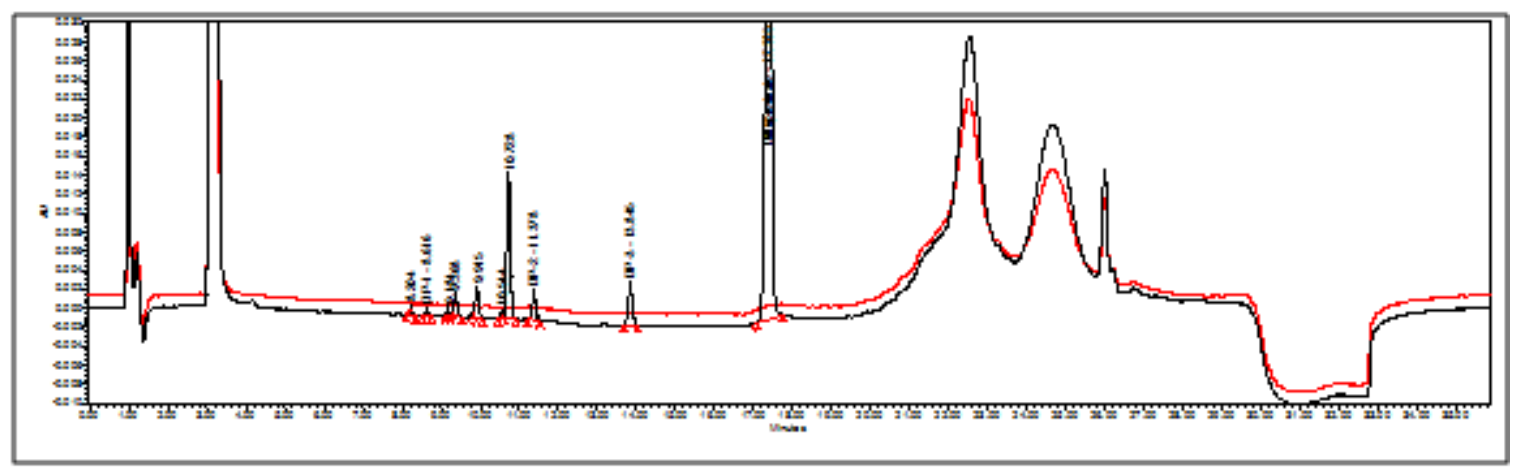

Fig. 5: Chromatogram of alkali hydrolysis sample and placebo

\section{Forced degradation studies}

Forced degradation studies were carried under conditions of acid/base hydrolysis, oxidation, heat and photolysis. For each study, samples and placebo were subjected to different stress conditions. The concentration of the reagents and the time of exposure was optimized to obtain degradation within the range of 5-20\%. During optimization of degradation conditions, excessive degradation was 
observed in the acid, base and peroxide degradation; the conditions were then optimized to get degradation between $5-20 \%$ which shall avoid generation of secondary degradation products.

During the forced degradation studies the sample was found to be very susceptible to base-catalyzed hydrolysis. The sample was also prone to acid catalysed hydrolysis and oxidation, which is shown in fig. 5-7. Throughout the degradation study, three major peaks were observed, which were also observed in the market sample too, these degradation products are then named as DP- 1 , DP- 2 and DP-3. Further work in future needs to be done for the identification of these impurities. The degradation products observed under these conditions were well resolved from the drug peak. Thus the developed method was considered stability indicating. The optimized degradation conditions and results were summarised in table 12.

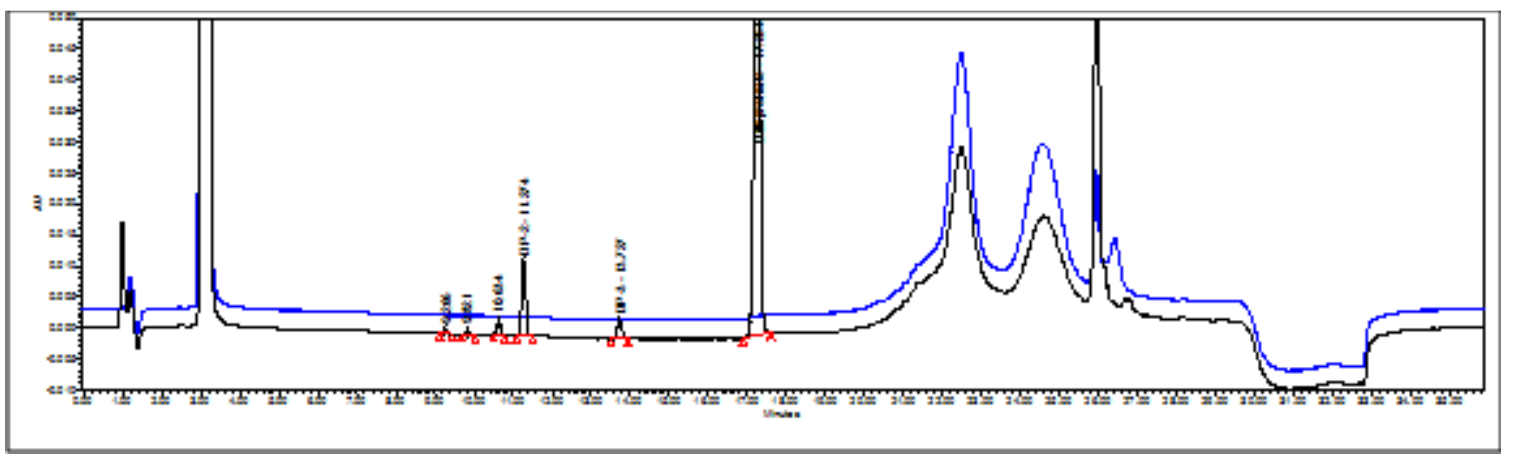

Fig. 6: Chromatogram of acid hydrolysis sample and placebo

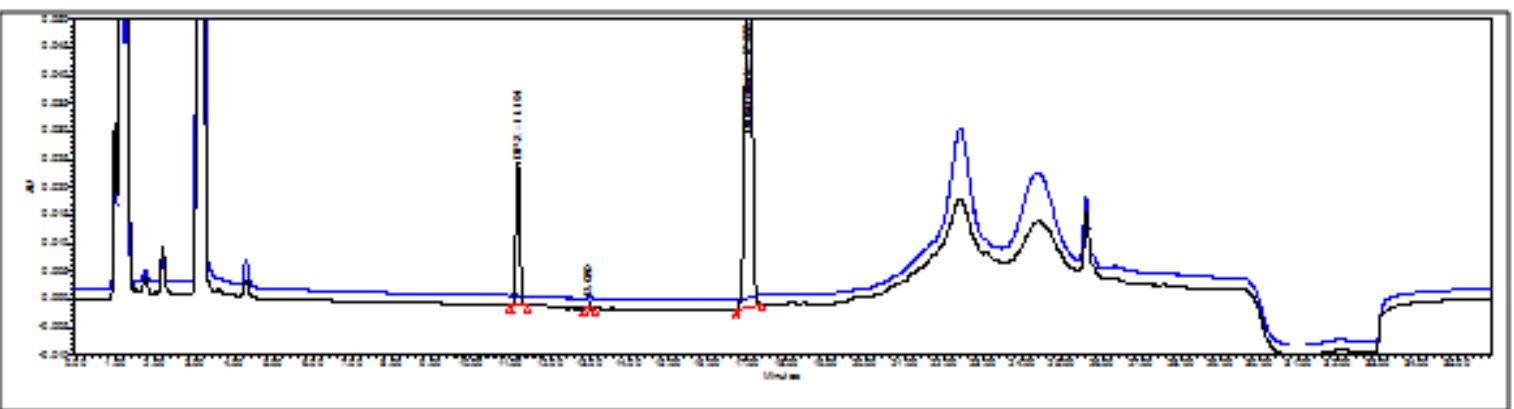

Fig. 7: Chromatogram of peroxide degradation sample and placebo

Table 12: Degradation behaviour of DIFL

\begin{tabular}{llllll}
\hline Condition for degradation & DP1 (\%) & DP2 (\%) & DP3 (\%) & \%Unknown & \% Total degradation \\
\hline $0.2 \mathrm{M} \mathrm{HCl}$ at $60^{\circ} \mathrm{C}$ for $10 \mathrm{~h}$ & 0.00 & 6.67 & 1.91 & 1.82 & 10.40 \\
$0.025 \mathrm{M} \mathrm{NaOH}$ at $40{ }^{\circ} \mathrm{C}$ for $6 \mathrm{~h}$ & 0.25 & 1.37 & 2.10 & 9.40 & 13.12 \\
Thermal degradation for $3 \mathrm{~d}$ & 2.23 & 1.18 & 1.54 & 3.73 & 8.68 \\
$6 \%$ Peroxide at $60{ }^{\circ} \mathrm{C}$ for $3 \mathrm{~h}$ & 0.00 & 18.87 & 0.23 & 0.530 & 19.64 \\
UV light at 254 for $7 \mathrm{~d}$ & 0.00 & 0.00 & 0.00 & 0.00 & 0.00 \\
\hline
\end{tabular}

${ }^{*} \mathrm{HCl}$ : Hydrochloric acid, $\mathrm{NaOH}$ : Sodium hydroxide.

\section{DISCUSSION}

Based on the results of forced degradation in the present study, three major degradation products were identified; these degradation products were also observed in the marketed products. The validation data indicates that the present work complies as per the ICH guideline [2]. The method was found specific, accurate, precise and robust for determination of all degradation products. The LOD and LOQ value were 0.1 and 0.15 respectively for the three degradation products (DP-1, DP-2 and DP-3). Low LOD and LOQ value indicates the sensitivity of the method for determination of degradation product in the ophthalmic emulsion. The high value of the correlation coefficient (more than 0.99) for DIFL and its degradation products indicates good linearity. The recovery of the method for the DIFL and the three impurities was found to be within $90-110 \%$, showing good recovery of the impurities. The precision of the method shows the reproducibility and repeatability of the method. The \% RSD value for the impurities was found to be less than $5 \%$, confirming the precision of the method for the quantitative determination of degradation products of DIFL. The specificity of the method to accurately quantify the degradation products of DIFL in the presence of the formulation components was proved by the forced degradation studies. The robustness data of the analytical method proves that the method was robust enough to deal with small changes in the method parameters. The methods available in the literature mostly focused on the assay of DIFL in the ophthalmic emulsion and in rabbit aqueous humor [4-10]. The present work specifically focused on the identification of degradation products and its quantification. This method can be used for evaluation of impurities in the market samples.

\section{CONCLUSION}

The developed method was stability indicating where well-resolved peaks were observed for analyte and degradation product. The method was specific, accurate, precise, and robust and can be used for routine quality control as well as accessing the stability of DIFL in bulk and in pharmaceutical dosage forms. 


\section{ACKNOWLEDGMENT}

The authors wish to express their gratitude to the management of Ramanbhai Patel College of Pharmacy, Charotar University of Science and Technology, and Sun pharma for providing the material and facilities for the experimental work to complete.

\section{AUTHORS CONTRIBUTIONS}

Conception or design of the work has been done by Murlidhar V. Zope; data Collection has been done by Ms Ashwinikumari Patel and Mr Murlidhar V. Zope; data Analysis and interpretation has been done by Mr Rahul M Patel and Mr Murlidhar V Zope; drafting the article has been done by Mr Rahul M Patel and Mr Murlidhar V Zope; Critical revision of the article has been done by Mr Murlidhar $\mathrm{V}$ Zope; final approval of the version to be published was provided by Dr Samir G. Patel.

\section{CONFLICT OF INTERESTS}

Declared none

\section{REFERENCES}

1. ICH harmonized tripartite guideline, Q2A (R2) stability testing of new drug substances and product. Geneva: International Conference on Harmonization; 2003.

2. ICH harmonised tripartite guideline, Q2 (R1) validation of analytical procedures: text and methodology. Geneva: International Conference on Harmonization; 2005.

3. ICH harmonised tripartite guideline, Q1B stability testing: photostability testing of new drug substances and products. Geneva: International Conference on Harmonization; 2005.

4. Shin Ichi Y, Masako K, Akira O, Kazuaki K. Analysis of an antiinflammatory steroidal drug, difluprednate, in aqueous humor by a combination of semi-micro HPLC and column switching method. J Pharm Biomed Anal 2003;30:1735-42.

5. Inoue J, Yamaguchi M, Sakaki H, Kida T, Tajika T. Preclinical pharmacokinetics of difluprednate emulsion. Invest Ophthalmol Vis Sci 2007;48:2651.
6. Mangukiya RP, Patel RA, Shah PA, Patel KG. Chromatographic methods for simultaneous determination of moxifloxacin hydrochloride and difluprednate in the ophthalmic dosage form. Acta Chromatographica 2015;27:495-8.

7. Patel P, Patel D, Meshram D. Validated RP-HPLC method for simultaneous determination of difluprednate and gatifloxacin in opthalmic emulsion. Int J Adv Res 2014;2:484-92.

8. Pradhan PK, Patel M, Mavani D, Raiyani N, Upadhyay U. RPHPLC method development and validation for simultaneous estimation of moxifloxacin and difluprednate in their combined dosage form. J Drug Delivery Thera 2014;4:60-5.

9. Nagaraju P, Siddartha V, Priyadarshini IG. New drug approval process in singapore-a detailed dissertation for registration of multi-source drug products. Int J Pharm Chem Sci 2015;4:61-6.

10. Patel P, Patel D, Desai S, Meshram D. Development and validation of analytical methods for simultaneous estimation of difluprednate and gatifloxacin in ophthalmic emulsion by uvvisible spectroscopy. Int J Pharm Sci Invent 2014;3:1-10.

11. ICH harmonised tripartite guideline, Q3B (R2) impurities in new drug products. Geneva: International Conference on Harmonization; 2006.

12. Mohammed IB, Prakash VK, Krishna MG. RP-HPLC method for simultaneous estimation of metformin and vildagliptin in bulk and its tablet formulation. J Global Trends Pharm Sci 2012;3:747-54.

13. Pratik Kumar Gupta, Vibha Chaturvedi. A study on forced degradation and validation of stability indicating RP-HPLC method for determination of benzalkonium chloride in azelastine hydrochloride pharmaceutical ophthalmic formulation. Asian J Pharm Clin Res 2017; 10:374-82.

14. Babu C, Narasimha Rao KL, Devanna N, Suresh Reddy KVN. Development and validation of stability indicating reversed phase high performance liquid chromatographic method for the determination of related substances in fampridine drug substance and tablet dosage forms. Asian J Pharm Clin Res 2017; $10: 334-8$ 